\title{
Sustainability of Comprehensive Universal Long-term Care Insurance in the Netherlands
}

\section{Frederik T. Schut and Bernard van den Berg}

\begin{abstract}
The Netherlands was the first country that introduced a universal mandatory social health insurance scheme for covering a broad range of long-term care (LTC) services provided in a variety of care settings. Compared with most other OECD countries, both total and public expenditure on LTC is high, particularly since the Dutch population is relatively young. On the other hand, coverage of LTC services is relatively comprehensive. In this article we examine the past experiences, current deficiencies and future prospects of LTC financing in the Netherlands. By rationing of supply and tight budgetary restrictions, the government managed to effectively control the growth of LTC expenditure, but at the expense of growing waiting lists and deteriorating quality of care. Reform plans aim to make the LTC system more efficient and consumer-directed. We discuss whether the proposed reforms offer a perspective on a sustainable system of comprehensive LTC insurance. This is especially important in view of the ageing of the population and the expected increase in demand for LTC services. We conclude that the success of the reforms heavily depends on the definition of entitlements, the accuracy of needs assessment and the feasibility of determining appropriate client-based budgets.
\end{abstract}

\section{Keywords}

Long-term care; Social health insurance; Health care reform; The Netherlands

\section{Introduction}

In many OECD countries public expenditures on health and long-term care (LTC) are a matter of great concern in view of an ageing population and increasing constraints on public budgets. These concerns are particularly vexing for countries with relatively high public expenditures on LTC, such as the Netherlands. In comparison to most other OECD countries, both total and public expenditures on LTC in the Netherlands are high, particularly since the percentage of elderly people is similar to the OECD average (OECD 2005). This can at least partly be explained by the relatively generous social health insurance scheme.

Address for correspondence: Frederik T. Schut, Institute of Health Policy and Management, Erasmus University, PO Box I738, 3000 DR Rotterdam, The Netherlands.Email: schut@bmg.eur.nl 
Nevertheless, the growth of public spending on health and long-term care in the Netherlands was quite successfully limited until 2000 via the implementation of cost-containment policies. These policies acted essentially through the rationing of supply, wage moderation, price controls and postponement of investment in LTC facilities. However, increasing waiting lists and rising consumer expectations about the quality and variety of LTC services have substantially reduced the scope for containing LTC expenditures along these lines. Hence, the Dutch government is aiming to reform the current long-term care financing system to increase incentives for efficiency and consumer direction.

The main aims of this article are (I) to describe the background, past experience and proposals to reform the system of LTC financing in the Netherlands; and (2) to discuss whether the proposed reforms can create incentives to keep the comprehensive LTC insurance scheme sustainable in view of the ageing of the population and the expected increase in demand for LTC services.

The second section provides a short background of the Dutch public health insurance scheme. In the following section we discuss the main features of the current public insurance scheme, before analysing the empirical evidence on the growth of public expenditure on LTG over the period $1985^{-2005}$. The subsequent section describes the relation between professional and informal care, before focusing specifically on the implications of the introduction of the personal care budgets for the provision of informal care. Next we discuss the projections and determinants of future long-term expenditure growth. The following section discusses the shortcomings of the current system of longterm care financing, and then the proposals for reforming the system. Finally, we discuss the prospects of the reform and the questions that remain to be answered.

Since a uniform definition is lacking, we will first indicate what we mean by long-term care. Often LTC is used only in the context of elderly care. In this article, however, we use a more comprehensive definition, including also care for the mentally and physically handicapped and care for chronic psychiatric patients. This definition coincides with the types of services covered by the public insurance scheme for long-term care in the Netherlands.

\section{Background of Public LTG Insurance}

The Netherlands was the first country to introduce a universal mandatory social health insurance scheme (the Exceptional Medical Expenses Act, abbreviated as AWBZ) for covering a broad range of LTC services provided in a variety of care settings. Whereas in the Netherlands public LTC insurance had already been introduced in I968, other countries followed only quite recently, like Germany in 1995 (see Rothgang, this issue) and Japan in 2000 (Ikegami 2007).

There are several reasons why in the Netherlands the choice was made for a separate universal public health insurance scheme for long-term care. First, prior to I968 the financing of LTG facilities was highly fragmented and increasingly insufficient to provide access to adequate care for lower-income 
groups. The strong economic growth during the ig6os substantially increased the general welfare of society, but because of a lack of adequate funding the availability and quality of LTC facilities lagged behind this overall welfare increase. Hence, since the financial risk of LTG was considered to be largely uninsurable on a private market, ${ }^{1}$ there was broad political support to expand public financing for it.

Second, because of the presence of a social health insurance scheme for curative health services (the Sickness Fund Act, abbreviated as ZFW) the choice was made for public insurance rather than tax financing (as, for instance, in Sweden and Norway). However, the prevailing sickness fund scheme covered only two-thirds of the population (primarily lower- and middle-income groups). Therefore, a straightforward expansion of this scheme by including long-term care in the mandatory benefits package was no option, because then the higher-income groups would not be included and would not have to contribute to the financing of long-term care. An option would have been to expand the prevailing mandatory social health insurance scheme from two-thirds to the entire population, alongside an expansion of the benefits package to include long-term care. Although this option was seriously considered and actually proposed by the government, the proposal was soon withdrawn because of strong resistance from private health insurers (fearing a substantial loss of business), employers (fearing increasing employer contributions) and the medical profession (fearing government control of fees for services to privately insured patients). Since an expansion of the prevailing social insurance scheme was not feasible (as, for instance, in Belgium and Switzerland), a separate mandatory insurance scheme for long-term care (AWBZ) for the entire Dutch population was proposed and enacted in Ig68.

Initially, the AWBZ covered primarily nursing home care, institutionalized care for the mentally handicapped, and hospital admissions lasting more than a year. In due course, however, coverage was expanded by including home health care, e.g. for rehabilitation at home after hospital admission and care for elderly people with impairments (in I980), ambulatory mental health care (in I982), family care, e.g. home help in case of frailty, psychosocial problems or after childbirth (I989) and residential care for the elderly (I997). In homes for the elderly (residential care) residents receive nursing care less frequently and intensively than do residents in nursing homes. Moreover, residents in elderly homes have their own apartments, while residents in nursing homes usually share a room with one or more other residents.

\section{Main Features of Public LTG Insurance}

The AWBZ constitutes a mandatory insurance scheme for long-term care for the entire Dutch population. Every Dutch citizen older than I5 years of age with a taxable income has to pay an income-related contribution (up to a certain maximum amount) that is collected through the income and payroll tax systems, along with the contributions for the other national insurance schemes (e.g. for unemployment and disability). In addition, for most LTC services covered by the AWBZ, income-related co-payments are required. For higher-income groups the maximum co-payment can be so high (about $€_{\mathrm{I}}$,8oo 
Table I

Funding of the AWBZ scheme in 2008

\begin{tabular}{lcc}
\hline \multicolumn{1}{c}{ Sources of funding } & $\begin{array}{c}\text { Payments } \\
\text { (billion euros) }\end{array}$ & $\begin{array}{c}\text { Share of total } \\
\text { payments (\%) }\end{array}$ \\
\hline Income-related contributions* & I3.I & 68 \\
Co-payments & I.7 & 9 \\
State subsidy (from general taxation) & 4.6 & 24 \\
Total & 19.3 & 100 \\
\hline
\end{tabular}

*In 2008 the income-related contribution was I2.I5 per cent of a maximum of $€_{31,589}$ taxable income (implying a maximum contribution of $€_{3}, 838$ per year, exclusive of various possible tax deductions).

Source: SER (2008: 3I).

Table 2

Different groups of AWBZ beneficiaries by numbers and expenditures in $2007^{*}$

\begin{tabular}{lrccc}
\hline \multicolumn{1}{c}{ Type of LTC user } & Number & $\begin{array}{c}\text { Share of } \\
\text { total number } \\
(\%)\end{array}$ & $\begin{array}{c}\text { Expenditure } \\
\text { (billion euro) }\end{array}$ & $\begin{array}{c}\text { Share } \\
\text { of total } \\
\text { expenditure } \\
(\%)\end{array}$ \\
\hline Elderly and chronically ill & 360,000 & 69 & II.4 & 65 \\
Mentally handicapped persons & I00,000 & I9 & 4.6 & 26 \\
Physically handicapped persons & I5,000 & 3 & 0.5 & 3 \\
Chronic psychiatric patients & 50,000 & 9 & I.I & 6 \\
Total & 525,000 & 100 & I7.6 & 100 \\
\hline
\end{tabular}

*Excluding about 90,ooo clients with a personal care budget (expenditure $€_{\mathrm{I} .3}$ billion). Source: SER (2008: 34).

per month for residential care) that private facilities are often more attractive. Income-related contributions and co-payments, as well as an annual state subsidy are collected in a General Fund (abbreviated as AFBZ).

Table I provides an overview of the different sources of funding of the AWBZ in 2008. Since in the same year the total expenditures from the General Fund were $€_{2 \mathrm{I} .4}$ billion, there was an overall deficit of $€_{2 . \mathrm{I}}$ billion (to be compensated by an extra increase in the 2009 contribution rate). As shown in table I, more than 75 per cent of the AWBZ is financed directly by households, while the residual amount is paid by the state out of general taxes. Table 2 provides an overview of the most important categories of LTG users and their relative share in LTC expenditure.

Formally, the AWBZ is administered by health-care insurers which provide coverage for curative health services. In practice, however, health-care 
insurers have delegated various responsibilities - in particular the contracting of health-care providers, the collection of patient contributions and the organization of regional consultations - to the largest regional health-care insurer. At present, the Netherlands is divided into 32 care regions and in each region a single health insurer (known as 'regional care office') carries out the AWBZ on behalf of all health insurers for all residents living in that region. Regional care offices receive a fixed budget for the administrative tasks. All LTG expenses are directly paid out the General Fund (AFBZ). Hence, neither regional care offices nor individual health insurers are at risk for long-term care expenses covered by the AWBZ scheme.

Before a person can qualify for care under the AWBZ, it is necessary to establish whether care is really required and, if so, what type of care and how much care is needed. Initially, health-care providers were responsible for the required needs assessment, but in I997 this task was assigned to regional independent needs assessment organizations, and since 2005 to a single national organization (the Centre for Needs Assessment, abbreviated as CIZ). ${ }^{2}$ The idea behind this was to make needs assessment more objective and uniform, and independent from the self-interest of health-care providers. Notice that the access to LTC is solely based on a person's health - as in Germany and Japan - and does not depend on his/her income or wealth like the Medicaid programme in the USA. ${ }^{3}$

Prior to 2003, the LTG benefits covered by the AWBZ scheme were defined in terms of the type of care or the type of health-care provider people were entitled to. To encourage innovation, consumer choice and an efficient substitution of LTC services, in 2003 the definition of entitlements was radically changed into seven broad functional care categories. In 2007 one of these categories - domiciliary care - was excluded from coverage and transferred to the responsibility of the municipalities under a new Social Support Act (abbreviated WMO). The remaining six functional categories of LTG services that were covered under the AWBZ scheme in 2008 are summarized in box I. ${ }^{4}$

Except for the functional category 'accommodation', clients who are entitled to care have a choice of receiving it 'in kind' or in the form of a personal care budget (or a combination of both). The personal care budget is set at about 75 per cent of the average cost of care provided 'in kind' because this budget can be spent on informal care, which is expected to be less expensive than professional formal care.

\section{Expansion of LTG Services and Expenditure, 1968-2005}

The enactment and gradual expansion of the public long-term insurance scheme (AWBZ) paved the way for a strong growth of long-term care facilities and of public expenditure on LTC. The percentage of GDP spent on longterm services covered by AWBZ increased from o.8 per cent in I968 to 2.o per cent in I980 and further to 4.o per cent in 2005. Part of this increase, however, is due to an expansion of AWBZ coverage.

As shown in figure I, from I985 to 2000 the percentage of GDP spent on LTG services that were covered by AWBZ in 2000 was more or less stable, around 3.5 per cent (in I985, however, only 2.0 per cent was covered by 
Box I

Functional categories of care covered by AWBZ

I. Personal care: e.g. help with taking a shower, bed baths, dressing, shaving, skin care, going to the toilet, eating and drinking.

2. Nursing: e.g. dressing wounds, giving injections, advising on how to cope with illness, showing clients how to self-inject.

3. Supportive guidance: e.g. helping the client organize his/her day and manage his/her life better, as well as day care or provision of daytime activities.

4. Activating guidance: e.g. talking to the client to help him/her modify behaviour or learn new forms of behaviour in cases where behavioural or psychological problems exist.

5. Treatment: e.g. care in connection with an ailment, such as serious absent-mindedness.

6. Accommodation: e.g. some people are not capable of living independent lives, but require, for example, sheltered housing or continuous supervision in connection with serious absent-mindedness. In some cases, a client's care requirements may be too great to address in a home environment, making admission to an institution necessary.

AWBZ and I.5 per cent was financed in other ways). Hence, taking into account the expansion of AWBZ coverage, the expenditure on LTC services as a percentage of GDP has been quite constant over a considerable period of time. This is remarkable given the ageing of the population (albeit fairly moderate during that period) and the susceptibility of LTG to Baumol's cost disease due to the limited scope for productivity gains in the provision of care (Oliviera Martins and Maisonneuve 2006). Despite the introduction of new technologies in the area of healthy ageing, the quality of many LTC services is likely to remain highly dependent on the input of labour. Therefore, the scope of substituting capital for labour is limited. ${ }^{5}$

The main reason for the limited growth of public spending on LTC has been the implementation of cost-containment policies. Already in the I970s the entry and capacity of new LTG institutions was strictly regulated. For building and major investments in facilities a licence from the government was required, and only if investments were judged to be of sufficient priority was such a licence granted. Particularly important, however, was the introduction in I984 of a system of global budgeting for all inpatient long-term health services. In addition, especially during the ig8os the government successfully mitigated the wages of nursing personnel. In the I99os, prompted by an economic recession, the budgetary controls were expanded to include also home health care and other outpatient LTG services.

The persistent rationing of supply, postponement of investments and budgetary controls resulted in growing waiting lists and a general perception of a deterioration of quality, particularly compared to the general increase in standard of living and the rising expectations about the quality of care people would like to receive in old age. In 1999 the long waiting lists for home health care were successfully challenged in court. The court ruled that public LTC insurance entitled people to timely access to home health care, and that 
Figure I

Percentage of GDP spent on LTC services covered by AWBZ in the current year and in 2005, from 1985 to 2005

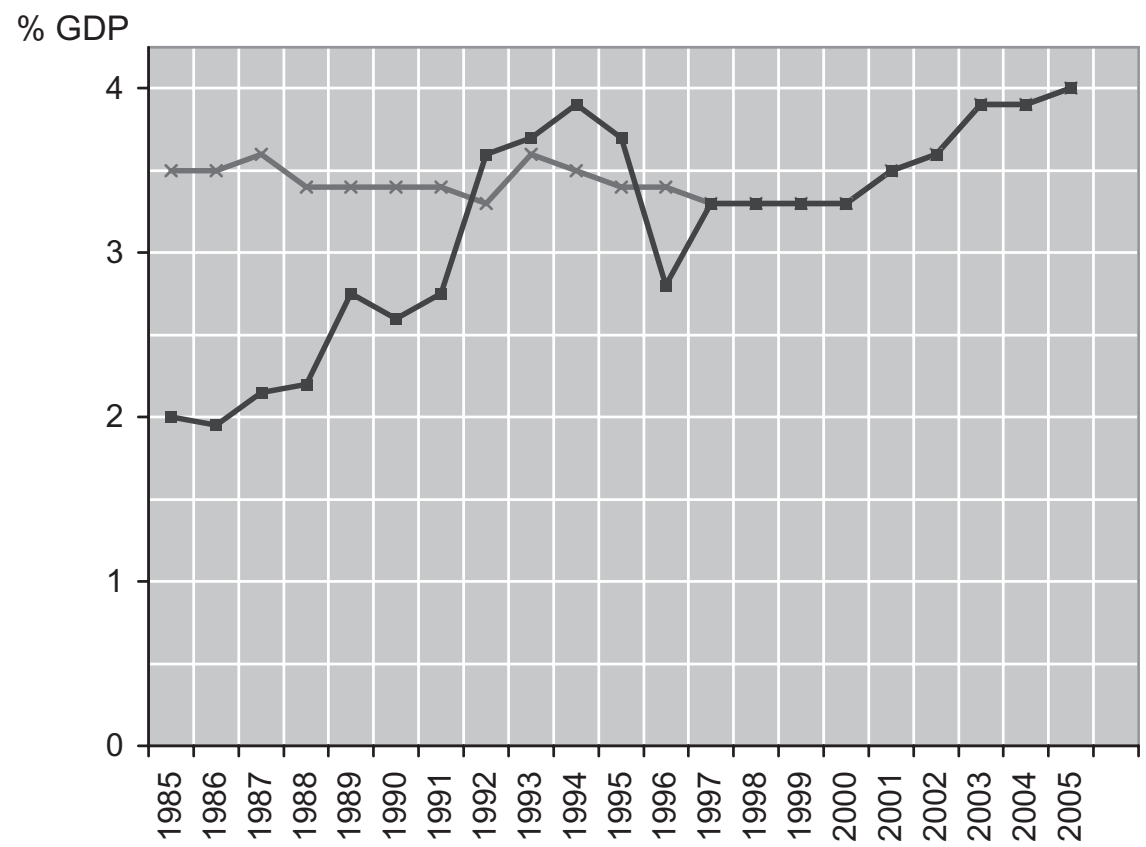

\section{* LTC services covered by AWBZ in 2005 \\ $\rightarrow$ LTC services covered by AWBZ in current year}

Note: From 1997 to 2005 the LTC services covered by AWBZ were the same as in 2005, so the two lines overlap. The bubble in the black line from 1992 to 1995 is caused by a temporary inclusion of outpatient drugs into the AWBZ benefits package.

Sources: Ministry of Health (2004); Eggink et al. (2008).

budgetary considerations were no valid reason for withholding care. In fact, the court decision implied that a too stringent rationing of health services was not compatible with the 'right to care' that was guaranteed by the social insurance legislation (AWBZ).

Urged on by the court decision and the mounting public and political pressure to improve access and quality of LTC services, in 2000 the government decided to lift the budgetary controls and to reimburse all extra production necessary to reduce waiting lists. Indeed, from 2000 to 2003 waiting lists were substantially reduced: for home health care by 64 per cent, for nursing homes by 39 per cent and for elderly homes by 23 per cent (Van Gameren 2005). As a consequence, during that period the expenditure on long-term care rapidly increased to more than io per cent per year (see 
Figure 2

Annual growth of LTC expenditures financed by public insurance (AWBZ)

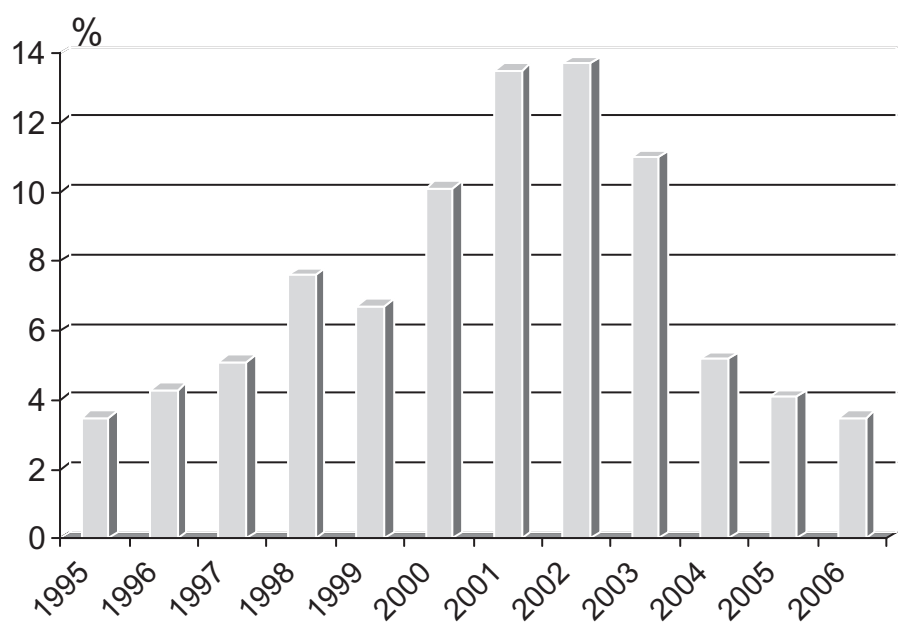

Source: IBO-werkgroep AWBZ (2006: 42).

figure 2), resulting in an increase from 3.5 to 4.0 per cent in the share of GDP spent on LTC (see figure I).

During the period I985-2005 the average annual growth of real expenditure on long-term care services covered by AWBZ was 3.3 per cent, whereas the average annual increase of GDP was about 2.7 per cent. The average difference of 0.6 per cent, however, is completely caused by the high cost inflation during the short period from 2000 to 2003. As shown in figure 3 , the largest share of expenditure growth can be explained by an increase in relative prices (2.0 per cent) while about I.3 per cent can be attributed to an increase in production. ${ }^{6}$

From figure 3 it can be concluded that for four of the five major categories of long-term care services the annual cost growth was about 4 per cent, which is well above the annual increase of GDP. This relatively high cost increase is largely compensated, however, by a relatively low cost increase of residential elderly care (on average about I.3 per cent per year). This is caused by a decrease in production (on average -0.7 per cent per year) due to reductions in the capacity of elderly homes and a substitution towards home health care. As a result, the annual production growth in home health care is the largest among the five categories of LTG services (on average about 2.5 per cent per year). Clearly, this reflects the trend that elderly people are treated at home for a longer period.

As shown in figure 4 , labour productivity for all LTC services decreased by 0.3 per cent over the entire I985-2005 period, contributing slightly to the overall price increase. This corroborates the supposition that Baumol's cost disease is particularly relevant for LTG services (Oliviera Martins and 
Figure 3

Average annual growth (\%) of LTC benefits covered by AWBZ, $1985^{-2005}$

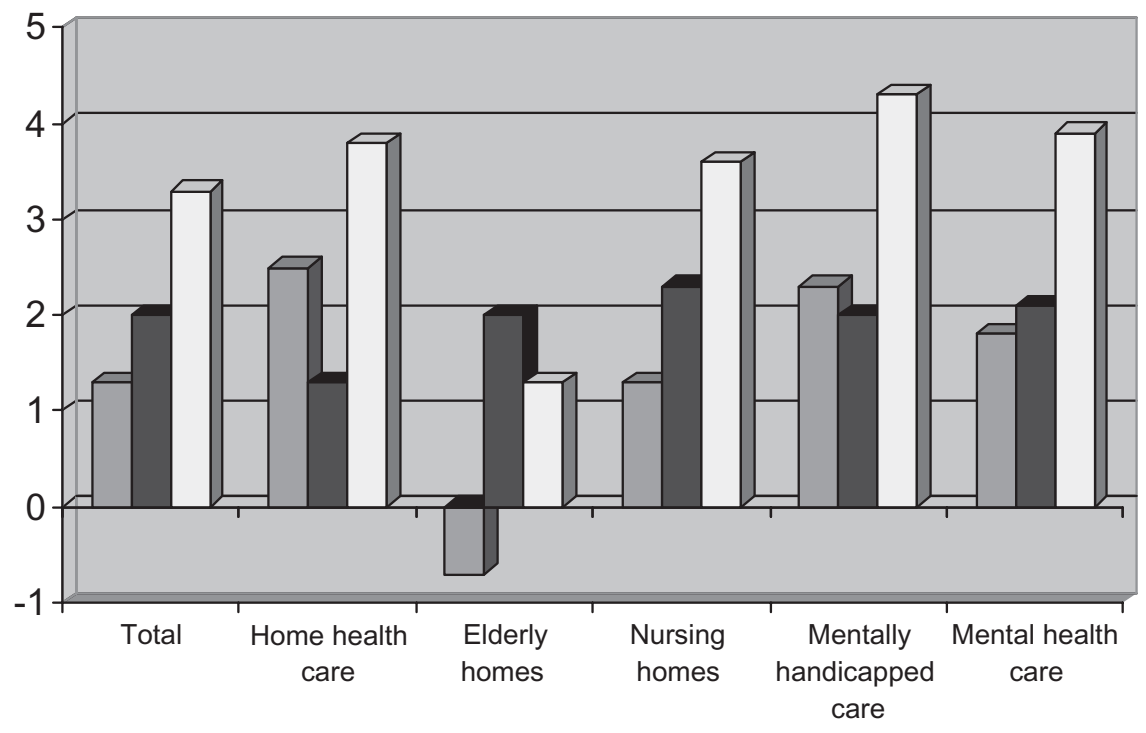

$\square$ Volume $\square$ Price $\square$ Total

Source: Eggink et al. (2008).

Maisonneuve 2006). Contrary to the general trend, labour productivity in home health care increased by on average 0.7 per cent per year during the same period. The increase in labour productivity in home health care has been particularly pronounced since r995 and is attributed to a tightening of the budgets for home health care agencies, resulting in a relative decline in administrative and managerial personnel and the introduction of benchmarking and time management to increase the efficiency of production (Eggink et al. 2008).

Looking at the development of long-term care expenditure in the period I985-2000, supply regulation and budgetary restrictions were clearly quite effective in containing cost. The downside of the prolonged rationing policies, however, was increasing waiting lists, resulting in a growing public discontent and incompatibility with the legally established entitlements to LTG services. For this reason, in 2000 a continuation of the prevailing cost containment strategy was no longer politically feasible. On the other hand, the radical change towards an open-ended reimbursement policy proved to be no solution either, since the resulting excessive cost inflation - without accompanying incentives for efficiency - was not sustainable. Already in 2004 the government tried to regain control over LTG expenditure by concluding agreements with the interest associations of LTC providers to limit 
Figure 4

Components of the growth of real prices of LTC benefits, $1985^{-2005}$

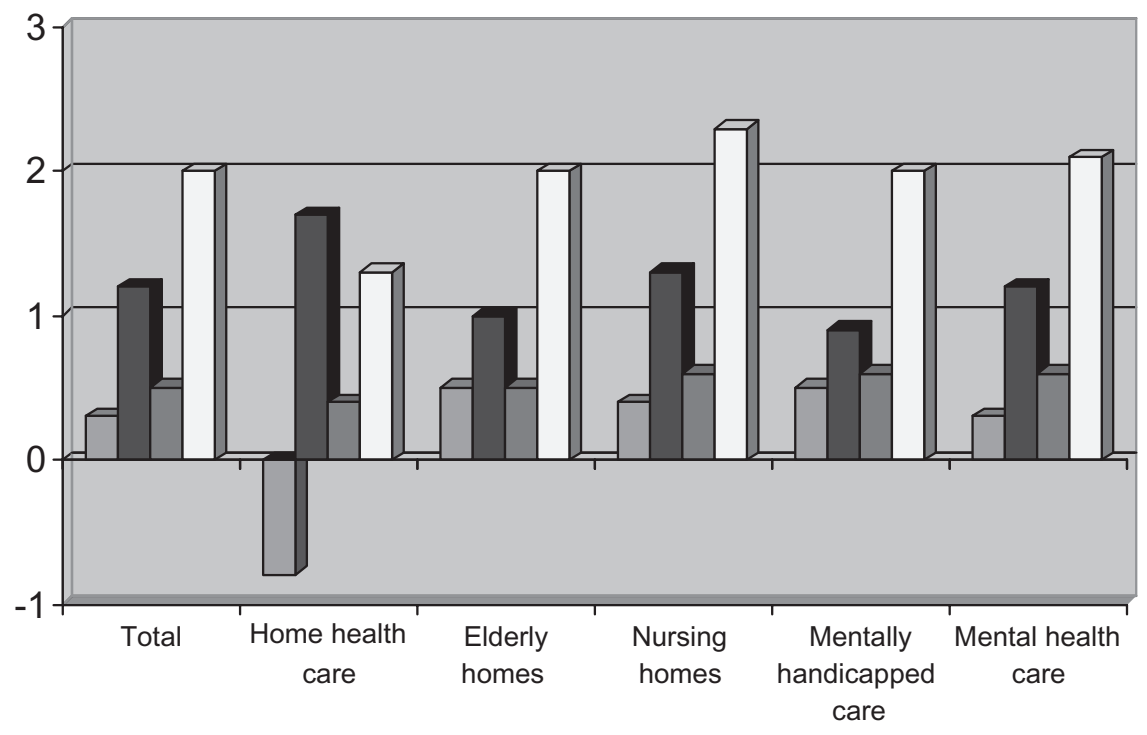

$\square$ Labour productivity $\square$ Hourly wages $\square$ Material cost $\square$ Total

Source: Eggink et al. (2008).

the growth of expenditure and to increase productivity. In addition, particularly for home health services, co-payments were increased. In 2005, the government reinstated budgetary controls by imposing regional budgets for each of the 32 regions, based on the past expenditure on LTC in that region. Regional care offices were made responsible for the allocation of these budgets and had to negotiate with regional providers about prices and maximum output levels. By reintroducing tight budget constraints, the government runs the risk that waiting lists will increase, which could again generate a conflict with the existing legal entitlement to LTC. In contrast to the late iggos, however, there is an important safety valve: the personal care budget. Since personal care budgets do not fall under the scope of the regional budget constraints, LTC providers can exceed their budgets if they can persuade their clients to apply for a personal budget and to use this to pay the provider. Indeed, this is one of reasons for the vast and increasing popularity of personal care budgets.

\section{Personal Care Budgets and Informal Care}

Personal care budgets were introduced in 1995 as a small-scale experiment to provide consumers with the option to buy and organize their own home 
health services instead of using 'in kind' services contracted by the regional care offices (Van den Berg and Hassink 2008). Since I995 the personal care budget scheme has been significantly expanded both in scope and expenditure. As of 2008 personal care budgets comprise about 7 per cent of longterm care expenditure covered by AWBZ and are used by more than Io per cent of LTC users. Table 3 provides some key figures about personal budgets in 2005 .

There were several reasons that were put forward for the introduction of personal care budgets (Hessing-Wagner I99o). First, such budgets were considered as a means to empower consumers and to motivate providers to better meet consumer preferences. During the I990s LTC providers were increasingly criticized for not being able to deliver the right services at the right time. Moreover, the new generation of LTC users had higher expectations and was supposed to be better able to express its preferences for LTC. By the option to choose a personal budget instead of contracted LTG services, people would be able to arrange care according to their own preferences.

A second reason for introducing personal care budgets was to encourage the use and provision of informal care as a cheap alternative to professional formal care. Informal care is a crucial part of long-term care all over the world. In the Netherlands, however, informal care plays a relatively minor

Table 3

Key figures of personal care budget in 2005

Number of budget-holders: 77,883

\begin{tabular}{|c|c|c|}
\hline Age distribution (years) & $\begin{array}{l}\text { I8-55 } \\
56-65 \\
66-75 \\
76-80\end{array}$ & $\begin{array}{r}32.5 \% \\
\mathrm{I} 2.6 \% \\
\mathrm{I} 4.3 \% \\
8.7 \%\end{array}$ \\
\hline Type of health problem & $\begin{array}{l}\text { Somatic } \\
\text { Psychogeriatric } \\
\text { Psychiatric } \\
\text { Physical handicap } \\
\text { Mental handicap } \\
\text { Sensory handicap }\end{array}$ & $\begin{array}{r}67 \% \\
\text { I } \% \\
\text { I } 4 \% \\
\text { I } 4 \% \\
\text { II } \% \\
\text { I } \%\end{array}$ \\
\hline Net budget amount (euros)* & $\begin{array}{l}<2,500 \\
2500-5000 \\
5000-25,000 \\
>25,000\end{array}$ & $\begin{array}{l}27.7 \% \\
24.9 \% \\
30.5 \% \\
16.9 \%\end{array}$ \\
\hline Proportion of budget spent on informal care & $\begin{array}{l}\text { Resident providers } \\
\text { Non-resident providers }\end{array}$ & $\begin{array}{l}21 \% \\
17 \%\end{array}$ \\
\hline
\end{tabular}

*Net of co-payments by budget-holder. The average gross personal care budget was about

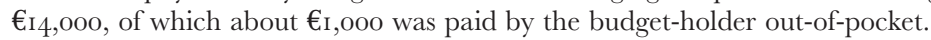

Source: Ministry of Health (2006). 
role, which is partly due to the relatively generous coverage of professional formal LTG services.

Using 2004 data from the Survey of Health Ageing and Retirement in Europe (SHARE) Albertini et al. (2007) show that within Europe the annual amount of informal care per caregiver is lowest in the Netherlands, Denmark, France and Sweden (around 300 hours) and highest in Italy (almost I,500 hours). Also using SHARE data, Bolin et al. (2008) show that the mean hours of received informal care by single-living elderly per year in the Netherlands is among the lowest within Europe (approximately 5o hours), while in Greece, Italy and Spain the single-living elderly receive the most informal care (over 200 hours). Conditional upon receiving informal care, the amount of care received by the single Dutch elderly is also among the lowest in Europe (about I3o hours per year).

In terms of professional home care use, the opposite pattern seems to hold. Bolin et al. (2008) show that the Netherlands (together with Denmark and France) belongs to the European top of professional home care use. Of single-living Dutch elderly, approximately 25 per cent use professional home care, while the proportion is the smallest in Italy (6 per cent).

Although the share of informal care in the Netherlands is lower than in most other European countries, still the majority of home care is provided by informal caregivers. Table 4 shows that in the Netherlands the amount of home care used in 200I was just around I 5 per cent of the total amount of informal care provided. Nevertheless, table 4 also shows the enormous growth of professional home care use (especially skilled housework) during the relatively short period $2000-3$.

The rapid expansion of personal care budgets was an effective way to encourage the provision of informal care. In 2005, some 38 per cent of personal care budgets were spent on informal care, while two-thirds of budget-holders use the budget for paying informal caregivers (Ramakers and Van den Wijngaart 2005). Next to personal care budgets, the role of informal care was also increased by restricting the possibilities for substituting professional for informal care. Initially, using informal care was considered to be people's voluntary choice. Even people having a social network with potential informal caregivers could always apply to get professional care that was covered by the AWBZ. In practice, however, the needs assessment agencies increasingly took into account the amount of informal care a client already received in order to determine the amount of professional care the client could legally claim (Jörg et al. 2002). Since 2003, this practice has been formalized, and strict protocols were developed regarding needs assessments, taking into account the potential amount of informal care the care recipient's social network could provide.

Another way to encourage the provision of informal care was to support informal caregivers. To prevent these caregivers getting health problems themselves, needs assessment agencies were permitted to refer caregivers to regional support centres. The support centres developed all kinds of respite care programmes, such as day care, short stays in nursing homes, holidays, and informational support (see e.g. Koopmanschap et al. 2004; Van Exel et al. 2006). 
Sogial Policy \& Administration, Vol. 44, No. 4, August 2010

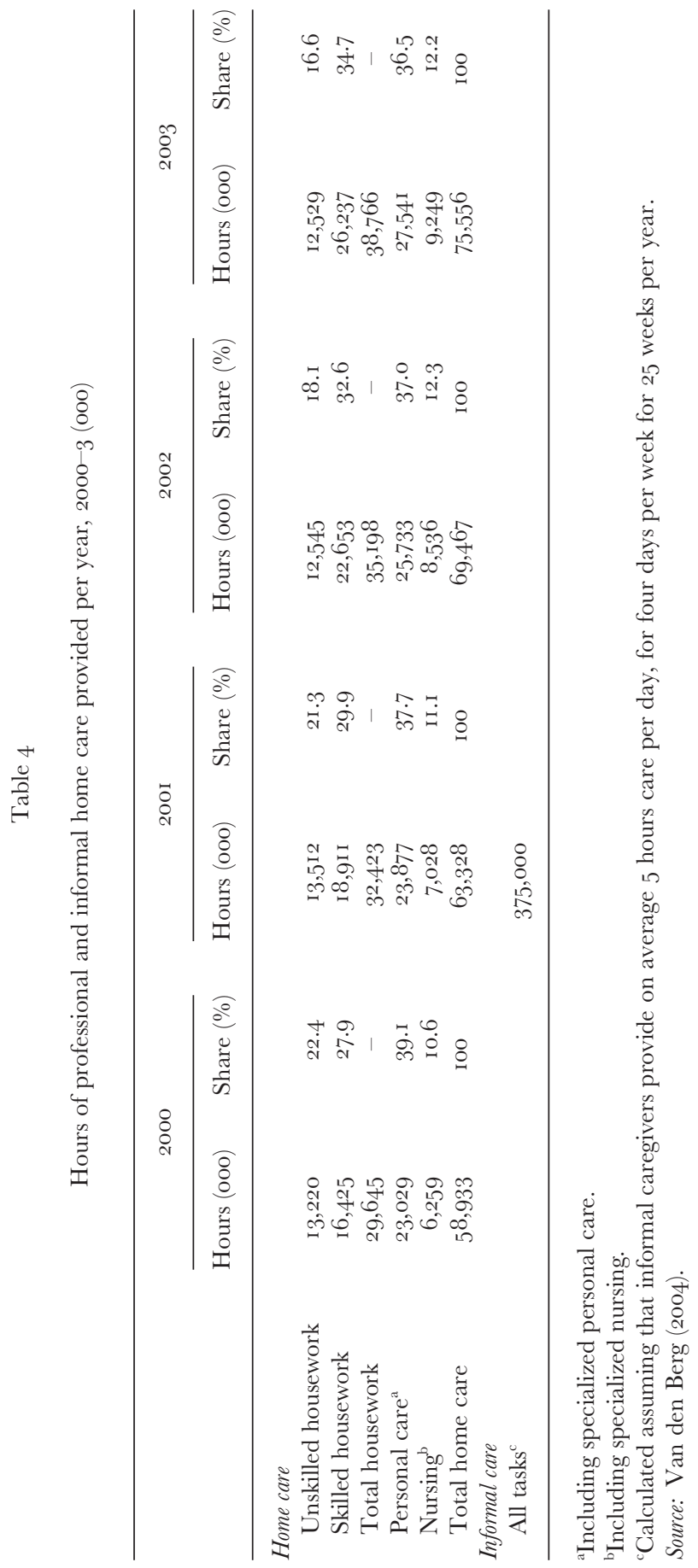


Evaluative studies point out that, as intended, personal care budgets induced a substitution of informal for professional care, and were valued by many clients as an effective means to purchase and organize care that better meets their preferences than regular care contracted by regional care offices (Ramakers et al. 2007). However, personal care budgets also had several unintended negative effects. First, they induced a substitution of paid for unpaid informal care. Informal care by relatives, neighbours and friends that previously was often provided for free, was becoming increasingly paid for. A study among informal caregivers pointed out that 76 per cent of the caregivers would be willing to provide the same care without receiving payment, although 78 per cent indicated that getting paid nevertheless was important to them (Ramakers and Van den Wijngaart 2005). In addition, an increasing number of brokers became active, who in return for a fee offered to assist people in applying for a personal care budget. Van den Berg and Schut (2003) calculated that a substitution of paid for unpaid informal care from the personal care budget could result in an increase of AWBZ costs of approximately $€_{4}$ billion per year (about 20 per cent of total AWBZ expenditure). ${ }^{7}$ Counteracting the substitution of paid for unpaid informal care was another reason for implementing the above-mentioned strict needs assessment protocols that explicitly take into account the amount of informal care that the recipient's social network could provide. According to the protocols, needs were not only based on health status or functional impairments but also on the availability of 'usual care'. For instance, the care partners provide to each other during at least three months is defined as usual care. Hence, the magnitude of the personal care budget became explicitly dependent on the social network of the beneficiary. Nevertheless, it is unclear to what extent people still can use personal care budgets for replacing unpaid with paid informal care. Especially, the fast-increasing number of personal care budgets for the assistance of young people with psychiatric disorders has been attributed to the substitution of paid for unpaid informal care provided by their parents.

A second drawback was that personal budgets were increasingly used by home health care agencies to escape the imposed budget constraints. As a consequence also, people who did not want to purchase and arrange care for themselves were more or less forced to do so in order to be able to keep the same home care provider.

It is difficult to assess to what extent personal care budgets were successful in accomplishing the aims behind their introduction. The rapidly increasing number of people opting for a personal care budget suggests that for a substantial proportion of users of outpatient LTC the budgets offered better opportunities to meet consumer preferences than care in kind. The problem is, however, that there is not much empirical information about the true motives of people to opt for the personal care budget. For instance, the growing demand for personal care budgets can at least partly be explained by the motivation to evade waiting lists for traditionally financed LTC and by consumer preferences to pay formerly unpaid informal caregivers. It is also unclear to what extent personal care budgets induced an efficient substitution of informal for formal care or just an expansion of paid informal care. For instance, the increasing number of parents opting for a personal care budget 
to provide care for their children seems to point to a substitution of paid for unpaid informal care. Moreover, for this group of clients it is unlikely that empowerment and better consumer-directed care were the main drivers to opt for a personal budget. In contrast, it seems fair to conclude that for people with long-term disabilities, personal care budgets really provide an instrument that helps them to empower themselves and to purchase care that better meets their preferences than care in kind.

\section{Projections of Future LTG Expenditure}

Future expenditure on LTC depends on a number of factors, both demographic and non-demographic. Several projections of future LTG expenditures have been made, which are not completely comparable because they are based on different definitions of LTG and use different assumptions and methodologies.

In a study about the drivers of public LTC expenditures (primarily elderly care), Oliviera Martins and Maisonneuve (2006) explicitly model the potential determinants of future LTG expenditure to project the expected share of GDP spent on LTG in 2050 for 30 OECD countries. The main results of their projections for the Netherlands and average OECD are summarized in table 5 .

Since the dependency on LTG increases sharply with age, demographic effects contribute to a substantial increase in LTG expenditures. The effects of ageing on LTC consumption might be mitigated by a 'healthy ageing' process if longevity gains are fully or partially translated in additional years of good health. Since the empirical evidence about the occurrence (and extent) of a healthy ageing process is mixed, Oliviera Martins and Maisonneuve (2006) assume that only half of the longevity gains are translated into a reduction in dependency. ${ }^{8}$ In addition, they also estimate the effect of a full healthy ageing process (compression of disability) and a complete absence of healthy ageing (expansion of disability).

In projecting future LTG expenditures, Oliviera Martins and Maisonneuve (2006) capture the Baumol effect by assuming that unit costs rise in line with aggregate labour productivity, a proxy for wage growth of care staff. As shown in table 5, this full Baumol effect induces a steady increase in relative prices, pushing LTC expenditures to 3.7 per cent of GDP in the Netherlands and to 3.3 per cent for the OECD countries on average. In addition, the effects of potential cost containment policies were simulated assuming that governments would be able to mitigate the cost pressures associated with the Baumol effect, by stimulating productivity gains and mitigating wage increase.

Under the base scenario, Oliviera Martins and Maisonneuve (2006) assume an income elasticity of zero, since they argue that LTG can be characterized as a necessity. Although empirical evidence of income elasticities for LTC are lacking, estimated income elasticities for health care in general are all above unity at a country level (Getzen 2000). This suggests that - at least for industrialized countries - health care can be considered as a luxury. Since the substitution of professional care for informal care can be seen as a luxury that 
Social Policy \& Administration, Vol. 44, No. 4, August 20 io

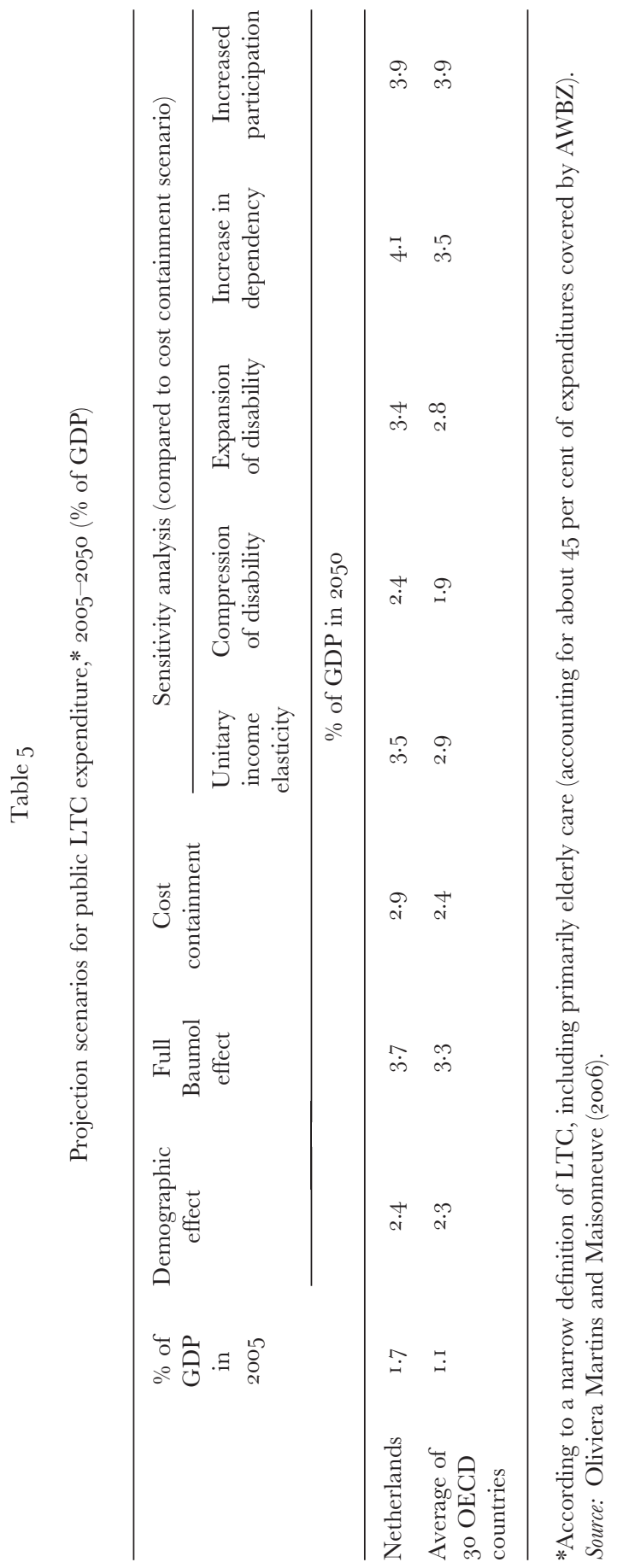


may be only publicly affordable if a country as a whole reaches a certain aggregate income level, long-term care may well be a luxury rather than a necessity. If this is true, the result of the sensitivity analysis using a unitary income elasticity may be more relevant. Table 5 shows that this implies that in $205^{\circ}$ an extra 0.5 per cent of GDP would be spent on LTC.

The authors also estimate the effect of an increase in dependency as a result of increasing disability rates (assumed to be 0.5 per cent per year) due to a continuation of the current trends in obesity. Finally, the authors examine the impact of an 'increased participation' scenario in which the availability of informal care is dramatically reduced by assuming that all countries converge towards a labour participation ratio in the age group of $5^{0}-64$ years (which is used as a proxy for the availability of informal care) of at least 70 per cent by 2050. As shown in table 5, both an increase in dependency and an increase in labour market participation are likely to have a substantial impact on LTC expenditure in the Netherlands and other OECD countries.

Specific projections of the future cost of LTC in the Netherlands have been made by the Netherlands Institute for Social Research (SCP) and the Dutch National Bureau for Economic Research (CPB). Based on the expected growth of the number of users, the SCP study projected an annual growth of expenditure on home health care, elderly homes and nursing home care of about I.3 per cent in constant prices for the period 2005-30 (Eggink et al. 2008). The projected increase in cost is higher than the projected increase in the number of users, which can be explained by the higher expected growth in the number of users of the most expensive LTC facilities (especially nursing homes).

The CPB followed another methodology to project future expenditure on LTG (SER 2008). After making the observation that expenditures on LTG are very sensitive to the type of government policy, the CPB made a distinction between two extreme scenarios. The first is based on a prolonged policy of supply and price regulation as in the period 1990-2000. Since during this period the annual growth of LTC expenditure was 0.6 per cent lower than the growth of GDP, the CPB assumes that under this scenario the same difference in growth would occur during the next decade. This would result in a decline in the proportion of GDP spent on LTG to 3.5 per cent in 2020 (using a broad definition of LTC, as in this article). The second scenario is based on a prolonged policy of laissez faire, as was prevalent from 2000 to 2006. During this period the annual rise in expenditure on LTC was about 3.8 per cent higher than the growth of GDP. Using this figure as the relevant difference under the second scenario, the resulting share of GDP spent on LTG in 2020 would be 6.4 per cent.

Since both extreme scenarios are unlikely, the 3.5 and 6.4 per cent of GDP can be perceived as lower and upper bounds on the LTC expenditure in 2020 (using a broad definition of LTG). The crucial role of health policy is in line with the observation by the OECD (2005) that the correlation across countries between LTC spending and ageing is rather weak, suggesting that the way of organizing and financing LTC plays an important role.

The overall conclusion that emerges from these projections is that the future expenditure on LTG are extremely uncertain and very sensitive to the 
exact growth of the number of elderly, changes in real prices of LTC (due to changes in labour productivity and the quality and intensity of care), changes in health policy, changes in labour market participation and trends in disability among the elderly.

\section{Deficiencies of Gurrent LTG Financing}

The projections of future expenditure on long-term care make clear that a laissez faire policy without supply and demand constraints (as in the period $2000-3)$ is likely to jeopardize the sustainability of the public LTC insurance scheme. On the other hand, a return to the stringent top-down rationing policy of the iggos has serious drawbacks and does not seem feasible either. Faced with this dilemma, the government has temporarily opted for a mixture of the two policies, half-heartedly relying on both supply constraints and arrangements to improve efficiency by increasing consumer direction and choice. For the following reasons, this inconsistent policy compromise can achieve neither cost containment nor an effective increase in efficiency.

First, the currently imposed supply constraints in the form of regional care budgets are not effective in controlling cost because they can be circumvented by opting for a personal care budget. Since personal care budgets are not included under the regional budget, the regional budget constraint is not binding. Although the government introduced a separate macro budget for personal care budgets, particularly since 2005 the demand for personal care budgets has been much larger than the available funds. Rather than denying personal care budgets, the government regularly adjusts the macro budget upwards to meet the growing demand. In 2007, for instance, the government decided four times to raise the budget, resulting in a total annual budget increase of 35 per cent (Ministry of Health 2007).

Second, the regional budget mechanism punishes providers who do a good job and consequently attract more clients than the target number on which their budget is based. If these presumably efficient providers cannot effectively motivate their clients to apply for a personal care budget, they have to refuse clients or run a deficit.

Third, regional care offices do not have an incentive to allocate the regional budget to the most efficient providers because they have a regional monopoly and are not at risk for the cost of care. Since LTG users cannot choose another regional care office, these offices have no incentive to allocate budgets to providers that best meet consumer preferences. Again, consumers may opt for a personal care budget (except for inpatient care), but this is not likely to discipline the behaviour of the regional offices because they do not benefit from having more customers. Moreover, since regional offices get a fixed budget for administrative cost, they have a financial incentive to negotiate with a limited number of large providers in order to minimize the cost of contracting. For the same reason, regional care offices have no incentive to take action against over-lenient needs assessment procedures.

Finally, the definition of entitlements in terms of six functional categories (see box I) has proven to be too imprecise to provide a firm basis for uniform and unambiguous needs assessment. In particular, the number of clients that 
were assessed to be in need of 'supportive guidance' increased dramatically, by 37 per cent from 2005 to 2007 (Ministry of Health 2008).

\section{Proposals to Reform LTG Financing}

In view of the serious deficiencies of the current system of LTC financing, the government asked a number of advisory and supervisory bodies ${ }^{9}$ to $\mathrm{draft}$ proposals for reforming the system of LTC financing in order to guarantee a sustainable, efficient and consumer-directed provision of LTC.

This resulted in five different advisory reports, which were not all equivocal. Reports by the Council on Health Insurance (CVZ) and the Council of Public Health and Care (RVZ) recommended the complete abolition of the separate public long-term insurance scheme. Most of the benefits covered by AWBZ had to be included into the new national Health Insurance Act for curative health services (abbreviated ZVW) and the remaining benefits (related to social support and participation) into the new Social Support Act (abbreviated WMO). The main line of reasoning was that the new health insurance scheme for curative services - based on the model of managed competition (Van de Ven and Schut 2008) - would provide much stronger incentives for efficiency and meeting consumer preferences than the AWBZ. Moreover, integrating curative and long-term care into a single scheme would also provide incentives and possibilities for a better coordination of care for people with chronic diseases. Next, the original reasons for a separate public insurance scheme (see the section on background, above) were no longer valid, since the mandatory insurance scheme for curative services was extended to the entire population in 2006. Finally, the 2007 Social Support Act (WMO) provided an integrated legal framework for social and community support under the responsibility of municipalities, so the transfer of social care benefits from the AWBZ to the WMO would also enhance a better coordination of social care and welfare assistance.

The radical proposals to abolish the AWBZ scheme, however, also had serious potential shortcomings. Most importantly, it is questionable whether the model of managed competition underlying the new health insurance scheme for curative services is adequate for the provision and financing of long-term care (Van de Ven and Schut i994). A key element of the managed competition model, which makes it possible to guarantee universal access in a competitive health insurance market, is an adequate system of risk adjustment (Van de Ven and Schut 2008). At present, there are no appropriate risk adjusters available for LTG and it is even unclear whether adequate risk adjustment is feasible for many of these services (IBO-werkgroep AWBZ 2006). Given the typically high level of expenditure per LTG user and the intertemporal nature of the risk, imperfect risk adjustment for these types of services may result in unfair competition among insurers and huge incentives for risk selection if insurers are obliged to charge community-rated premiums (as is the case under the 2006 Health Insurance Act). Another reason why the managed competition model may not be appropriate for LTC services is that for many of these services consumers are not able or willing to make an informed choice among health insurers that contract these services. There is 
substantial empirical evidence that the propensity to switch health plans substantially declines with age and the presence of health problems (Strombom et al. 2002; Schut et al. 2003; Buchmueller 2006). For LTC services for which the number of critical buyers is too small, competition may result in a deterioration of quality, since competitive health insurers may have an incentive to reduce quality in order to reduce cost if this does not result in a significant loss of market share (Van de Ven and Schut 1994). Finally, the experience with both the new Health Insurance Act and the new Social Support Act is limited and it is unclear whether health insurers and municipalities are willing and able to perform as prudent purchasers of health and social services. Therefore, a major expansion of the scope of the responsibilities of health insurers and municipalities would be premature.

In view of these shortcomings, other advisory reports proposed to maintain a separate insurance scheme for several categories of LTC, at least including care for the mentally handicapped. Among these reports, the proposal by the Social and Economic Council was the latest and the most important (SER 2008). The SER proposed to reform the AWBZ along the following main lines:

I. A much more precise and unambiguous delineation and definition of entitlements.

2. An improvement of the needs assessment by developing uniform protocols, benchmarking and a permanent supervision of the assessment bodies.

3. A reduction of coverage by transferring short-term rehabilitation services to the health insurance scheme for curative health services (Health Insurance Act) and by bringing the provision of social care under the responsibility of the municipalities (Social Support Act).

4. A far-reaching separation of the financing of accommodation and care, implying that accommodation would no longer be reimbursed by public insurance; a subsidy scheme for lower-income groups to pay for the cost of accommodation; the separation of care and accommodation should lead to innovative combinations of accommodation, care, welfare and participation.

5. A replacement of provider-based budgeting by client-based budgeting. Rather than clients having to follow the money - as in the current providerbased budgeting system - the money should follow the client. Clients would have the option to choose a personal care budget (as in the current system) and arrange all care by themselves, or to choose among providers contracted by individual health insurers (that would have to replace regional care offices in 2012). Providers can increase revenues if they are able to attract more clients by offering better service (for a fixed budget per client). The client-based budgets should be based on the categorization of clients in 'care-severity packages' (abbreviated ZZPs) by the needs assessment bodies. A 'care-severity package' describes the type and amount of care needed by the client. For each 'care-severity package' a budget will be calculated.

In June 2008 the government declared its endorsement of the main lines of the SER proposal and announced the first steps to implement its recommendations, including a more precise demarcation of entitlements and 
an exclusion of recovery and social support from coverage by 2009 (Ministry of Health 2008). In a subsequent policy letter by mid-2009, the reform plans were further elaborated (Ministry of Health 2009). In this letter the government stated its aim of abolishing the regional care offices in 2012 and instead making individual health insurers responsible for the purchasing and contracting of LTG services on behalf of their insured (next to maintaining the option for clients to choose a personal care budget or voucher and to purchase care by themselves). However, this decision is made contingent on the possibility of making health insurers financially accountable for the LTC expenses of their insured and on the feasibility of an adequate system of client-based budgeting.

\section{Towards Sustainable LTG Financing?}

Whether the proposed reform will lead to sustainable financing and more consumer-directed provision of long-term care services crucially depends on the ability to develop a clear-cut definition of entitlements, to improve the accuracy of needs assessment, ${ }^{10}$ and to develop appropriate 'care-severity packages' as a solid basis for client-based budgeting. The feasibility of these three requirements is highly uncertain. In particular, client-based budgeting may turn out to be complicated. In 2008, 'care-severity packages' (ZZPs) have been developed for inpatient care, which from 2009 to 20 I I will be phased in to determine the budgets for inpatient care LTC facilities (i.e. nursing homes, elderly homes, institutions for the mentally and physically handicapped and mental care institutions). The experience with these care-severity packages for financing inpatient care may make clear whether they can provide a firm basis for client-based financing. A key question will be whether the predictable cost variation per care package will be small enough to avoid problems of creamskimming and misallocation of funds. ${ }^{11}$ The first experiences with the introduction of client-based budgeting for inpatient LTC were evaluated by the Dutch Healthcare Authority (NZa 2009). The NZa reported that it received signals from both health-care providers and regional care offices of strategic upcoding (classifying clients in higher ZZPs than indicated) and risk selection (avoiding patients that are unprofitable given the ZZP capitation payment). The main reason put forward for such behaviour was that for several ZZPs or for several patients classified within a certain ZZP, capitation payments were insufficient to cover the costs. Based on the limited available data, the NZa could not determine whether upcoding and risk selection indeed occurred, but it announced its intention to monitor this type of behaviour and to examine the accuracy of ZZP payments.

An important, yet unanswered question is how future client-based budgets should be determined: should they be based on the average cost of all providers that offer the care package? Given the increasing pressure to contain public expenditure on LTG services, the most likely outcome may be that the client-based budgets will be derived from the regional budgets (or a national budget) set by the government, using the care-severity packages as relative weights for determining the (regional) level of the client-based budget for each care package. ${ }^{12}$ The way of determining the budget will be closely related to another still unanswered question, namely for which party the client-based 
budget should be binding. In other words, if the actual cost of providing a care package differs from the client-based budget, then who should bear the additional costs or keep the residual: the client, the provider, or the insurer contracting the provider? At present, providers receive the full ZZP capitation payments for each client they serve and neither clients nor regional care offices bear financial risk (except for the income-related co-payments clients have to pay). However, if risk-bearing health insurers replace regional care offices by 2012, it is conceivable that ZZP capitation payments will be given to the insurers, which subsequently have to negotiate prices per ZZP with various LTC providers.

In theory, the Dutch proposed reforms involve appropriate incentives to improve the sustainability of the comprehensive LTC insurance scheme. As argued, in practice the success of the reforms will depend heavily on the way entitlements are defined, an improvement of the accuracy of needs assessment and the feasibility of determining appropriate client-based budgets. For adequate client-based budgeting it is crucial that the care-severity packages that are currently being developed are relatively homogeneous in terms of predicted costs as substantial variation involves clear incentives for upcoding and risk selection.

Although the proposed reform offers a promising perspective to combine a sustainable and universally accessible LTG financing with a consumerdirected provision of care, a number of complicated issues have to be resolved. The Dutch experiences in implementing the reform may therefore provide important lessons for countries with a public insurance scheme for long-term care - e.g. Japan and Germany - that also struggle with the question of how to guarantee a sustainable, universally accessible and high-quality system of long-term care (Ikegami 2007; see also Rothgang, this issue). In addition, it may also provide important lessons for countries considering the introduction of a system of social insurance for long-term care (see Barr, this issue).

\section{Acknowledgements}

A previous draft of this article was presented at the 7 th World Congress of the international Health Economics Association (iHEA) in Beijing and at the International Conference on the Policies and Regulations of Health and Long-term Care Costs of the Elderly in Tokyo. Part of this research has been supported by a research grant to Hitotsubashi University from the Ministry of Education of Japan (grant number I800200I).

\section{Notes}

I. There are several reasons why private markets fail to provide adequate insurance for LTC. The absence of private LTC insurance has been explained (e.g. Cutler I996; Brown and Finkelstein 2007) by the nature of intertemporal risk, by supplyside market failure (resulting from high transaction costs, adverse selection and imperfect competition) and by demand-side factors such as limited consumer rationality, limited foresight, and the availability of imperfect but cheaper substitutes. 
2. As of 2008, this Centre for Needs Assessment (CIZ) has one main office, six district offices and 30 local offices.

3. Following the recently proposed typology by Ariizumi (2008), the Dutch public insurance system can be characterized as a health-based rather than a meanstested programme.

4. As of 2009, two functional categories - supportive and activating guidance - are combined into a single category 'guidance'. At the same time, guidance that is aimed at social participation is excluded from coverage and brought under the scope of the Social Support Act (WMO).

5. When productivity growth in the LTC sector lags behind that in other sectors while wages grow at the same rate, relative prices of LTC vis-à-vis other goods and services in the economy will rise. In the case of a low price elasticity of demand for LTC - which is likely in the presence of public insurance - the share of LTC expenditure in GDP will also increase over time.

6. Production of LTC services is measured by the Netherlands Institute for Social Research (Eggink et al. 2008) using indicators of production (e.g. admissions, day treatments, length of stay, number of patients, etc.) weighted by the type and intensity of treatment.

7. This number was based on the assumption that a substantial proportion of informal caregivers already get paid from the personal care budget (see also Van den Berg and Hassink 2008). Their average payment is around €⿱o per hour. Multiplication of this average payment with the informal care hours presented in table 4 makes approximately $€_{4}$ billion.

8. For the Netherlands this assumption might be an underestimation. In the Netherlands the ratio of disability-free life expectancy to life expectancy at age 65 was 79 per cent for men and 67 per cent for women in 2000 (OECD 2005). The ratio has increased since I990, particularly for women.

9. Specifically, the Social and Economic Council (SER), the Council for Public Health and Health Care (RVZ), the Health Care Insurance Board (CVZ), the Dutch Healthcare Authority (NZa), and a governmental working group (IBO).

Io. In the Japanese LTC insurance scheme, for instance, nationally uniform standardized eligibility criteria are used to determine which services the elderly are entitled to (Ikegami 2007).

I I. The determination of adequate ZZP capitation payments for outpatient LTC may be more complicated because the need for outpatient care crucially depends on the availability of a social network of informal caregivers, which typically varies substantially across individuals.

I2. Using national rather than regional budgets may be politically attractive because then government may avoid a socially controversial regional variation in the level of client-based budgets.

\section{References}

Albertini, M., Kohli, M. and Vogel, C. (2007), Intergenerational transfers of time and money in European families: common patterns - different regimes? Fournal of European Social Policy, I7: 319-34.

Ariizumi, H. (2008), Effects of public long-term care insurance on consumption, medical care demand, and welfare, Fournal of Health Economics, 27: 1423-35.

Bolin, K., Lindgren, B. and Lundborg, P. (2008), Informal and formal care among single-living elderly in Europe, Health Economics, I7: 393-409.

Brown, J. R. and Finkelstein, A. (2007), Why is the market for long-term care insurance so small? Fournal of Public Economics, 91: i967-9I. 
Buchmueller, T. C. (2006), Price and the health plan choice of retirees, Fournal of Health Economics, 25, I: 8I-IOI.

Cutler, D. (I996), Why don't markets insure long-term risk? Unpublished working paper. Available at: www.economics.harvard.edu/faculty/cutler/files/ltc_rev.pdf.

Eggink, E., Pommer, E. and Woittiez, I. (2008), De ontwikkeling van de AWBZ-uitgaven: een analyse van de AWBZ-uitgaven 1985-2005 en een raming van de uitgaven voor verpleging en verzorging 2005-2030 [The development of AWBZ expenditures: an analysis of AWBZ expenditures from 1985 to 2005 and a forecast of the expenditures on nursing and care for 2005-2030], The Hague: Sociaal en Cultureel Planbureau (SCP).

Getzen, T. E. (2000), Health care is an individual necessity and a national luxury: applying multilevel decision models to the analysis of health care expenditures, Journal of Health Economics, i9, 2: 259-70.

Hessing-Wagner, J. C. (I990), Cliëntgebonden budget en zorg: de individualisering van geldstromen nader beschouwd [Client-based budget and care: a closer look at the individualization of payment flows], The Hague: Sociaal en Cultureel Planbureau (SCP).

IBO-werkgroep AWBZ (2006), Toekomst AWBZ: Eindrapportage van de werkgroep Organisatie romp $A W B Z$ [The future of AWBZ: final report of the working group on the organization of the core AWBZ], Interdepartementaal Beleidsonderzoek 20042005, no. 4, The Hague.

Ikegami, N. (2007), Rationale, design and sustainability of long-term care insurance in Japan - in retrospect, Social Policy and Society, 6, 3: 423-34.

Jörg, F., Boeije, H. R., Huijsman, R., De Weert, G. H. and Schrijvers, A. J. P. (2002), Objectivity in needs assessment practice: admission to a residential home, Health and Social Care in the Community, Io, 6: $445^{-5}$.

Koopmanschap, M. A., Van Exel, N. J. A., Van den Bos, G. A. M., Van den Berg, B. and Brouwer, W. B. F. (2004), The desire for support and respite care: preferences of Dutch informal caregivers, Health Policy, 68: 309-20.

Ministry of Health (2004), Op weg naar een bestendig stelsel voor langdurige zorg en maatschappelijke ondersteuning [On track towards a sustainable system for long-term care and social support], Letter to parliament, DVVO-U-2475093, The Hague.

Ministry of Health (2006), Fact sheet personal budget AWBZ. Available at: www. minvws.nl/en/folders/zzoude_directies/dvvo/2005/fact-sheet-personal-budgetawbz.asp.

Ministry of Health (2007), Pgb in perspectief [Personal care budget in perspective], Letter to parliament, DLZ/ZI-U-28ıi8og (9 November), The Hague.

Ministry of Health (2008), Zeker van zorg, nu en straks [Assured care, now and later], Letter to parliament, DLZ/KZ-285677I (I3 June), The Hague.

Ministry of Health (2009), Nadere uitwerking toekomst van de AWBZ [Further details on the future of AWBZ], Letter to parliament, DLZ/CB-U-29I2I89 (I2 June), The Hague.

NZa (2009), Voortgangsrapportage Invoering ZZP's: Rapportage over de periode I januari 2009-30 juni 2009 [Proceedings on the implementation of ZZPs: report on the period I January 2009-30 June 2009], Utrecht: Dutch Healthcare Authority (NZa).

OECD (2005), Long-term Care for Older People, Paris: OECD.

Oliviera Martins, J. and Maisonneuve, C. de la (2006), The drivers of public expenditure on health and long-term care: an integrated approach, OECD Economic Studies, 43, 2: II5-54.

Ramakers, C. and Van den Wijngaart, M. (2005), Persoonsgebonden budget en mantelzorg: Onderzoek naar de aard en de omvang van betaalde en onbetaalde mantelzorg [Personal care budget and informal care: inquiry into the nature and extent of paid and unpaid informal care], Nijmegen: ITS/Radboud University. 
Ramakers, C., Graauw, K. de, Sombekke, E., Vierke, H., Doesborgh, J., and Wolderingh, C. (2007), Evaluatie persoongebonden budget nieuwe stijl 2005-2006 [Evaluation of the new version of the personal budget 2005-2006], Nijmegen: ITS/Radboud University.

Schut, F. T., Greß, S. and Wasem, J. (2003), Consumer price sensitivity and social health insurer choice in Germany and the Netherlands, International Fournal of Health Care Finance and Economics, 3: 117-38.

SER (2008), Langdurige zorg verzekerd: over de toekomst van de AWBZ [Long-term care assured: about the future of the AWBZ], Publicatienummer 3, The Hague: Social and Economic Council (SER).

Strombom, B. A., Buchmueller, T. C. and Feldstein, P. J. (2002), Switching costs, price sensitivity and health plan choice, Fournal of Health Economics, 21: 89-Ir6.

Van den Berg, B. (2004), Dragen de sterkste schouders de zwaarste lasten? Een discussie over de positie van mantelzorgers ten opzichte van de AWBZ-zorg [Do the strongest shoulders carry the heaviest burden? A discussion about the position of informal caregivers in relation to AWBZ care], Tijdschrift voor Politieke Ekonomie, 26: $24-37$.

Van den Berg, B. and Hassink, W. H. J. (2008), Cash benefits in long-term home care, Health Policy, 88: 209-2 I.

Van den Berg, B., and Schut, F. T. (2003), Het einde van gratis mantelzorg? [The end of free informal care?], Economisch Statistische Berichten, 88, 44I3: 420-2.

Van de Ven, W. P. M. M. and Schut, F. T. (I994), Should catastrophic risks be included in a regulated competitive health insurance market? Social Science and Medicine, 39, го: I459-72.

Van de Ven, W. P. M. M. and Schut, F. T. (2008), Universal mandatory health insurance in the Netherlands: a model for the United States? Health Affairs, 27, 3: $77 \mathrm{I}-8 \mathrm{I}$.

Van Exel, N. J. A., Morée, M., Koopmanschap, M. A., Schreuder Goedheijt, T. and Brouwer, W. B. F. (2006), Respite care: an explorative study of demand and use in Dutch informal caregivers, Health Policy, 78: 194-208.

Van Gameren, E. (2005), Regionale verschillen in de wachtlijsten verpleging en verzorging: Een empirisch onderzoek naar verklarende factoren [Regional variation in waiting lists for nursing and care: an empirical investigation of explanatory factors], Werkdocument irg, The Hague: Sociaal en Cultureel Planbureau (SCP). 